\title{
La identificación de las cabeceras de cuencas hidrográficas: métodos y aplicaciones
}

\author{
Juan Felipe Meléndez de la Cruz \\ Universidad Nacional Mayor de San Marcos \\ jmelendezd@unmsm.edu.pe
}

\begin{abstract}
RESUMEN
Las cuencas hidrográficas son grandes unidades naturales donde se plasma el ciclo hidrológico en los continentes, siendo el agua el elemento central. Normalmente, esas unidades se delimitan de manera cualitativa considerando una línea divisoria continua que de manera aproximada une los puntos de las partes altas de geoformas positivas como por ejemplo Montańas, colinas o lomas. Teniendo en cuenta el criterio natural del drenaje, la cuenca hidrográfica está estructurada por una red de corrientes o cauces y a su vez se pueden clasificar u ordenar. La mencionada red de drenaje a su vez se subdivide en subcuencas, una de ellas puede dar origen a la corriente principal que normalmente es un río y a su vez determinar la cabecera de la cuenca.

La clasificación de cuencas de drenaje es uno de los métodos conocidos universalmente para delimitar unidades y subunidades y que se debería tener en cuenta para resolver los problemas de delimitación de cabeceras de cuencas hidrográficas en nuestro país. Actualmente, en nuestro país existe la necesidad de señalar criterios técnicos para identificar cabeceras de cuencas hidrográficas. Este trabajo busca contribuir con el referido requerimiento técnico desde el punto de vista académico.
\end{abstract}

Palabras clave: Cuencas hidrográficas; orden de cauces; geoformas; subcuencas; cabeceras de cuenca.

\section{The identification of hydrographical watershed headwaters - methods and applications}

\begin{abstract}
Watersheds are large natural units where the hydrological cycle takes shape in the continents, with water being the central element. Normally, these units are delimited qualitatively considering a continuous dividing line that roughly joins the points of the high parts of positive geoforms such as mountains or hills.

Taking into account the natural criterion of drainage, the watershed is structured by a network of streams or channels and in turn can be classified or sorted. The aforementioned drainage network is subdivided into sub-basins, one or two of these can give rise to the main current that is normally a river and in turn determine the head of the basin.

The classification of drainage basins is one of the methods known universally to delimit units and subunits and that must be taken into account to solve the problems of delimitation of headwaters of watersheds in our country.

Currently, in our country there is a need to identify technical criteria to identify headwaters of watersheds. This work seeks to contribute to the referred technical requirement from the academic point of view.
\end{abstract}

KEYwORD: Watersheds; order of channels; geoforms; sub-basins; basin headwaters. 


\section{Elementos teóricos}

\section{Las cuencas y el ciclo hidrológico}

$\mathbf{L}$ as cuencas hidrográficas son grandes unidades naturales donde se plasma el ciclo hidrológico en los continentes, siendo el agua el elemento central. Esas unidades se delimitan de manera cualitativa considerando una línea divisoria continua que de manera aproximada une los puntos de las partes altas de geoformas positivas como por ejemplo Montañas, colinas o lomas. Solo si las montañas han sido modeladas por la erosión glaciar se tendría geoformas de pirámides o circos glaciares con agujas y se podría señalar cotas de considerable elevación.

Desde el punto de vista hidrológico los caudales de los cauces en una cuenca hidrográfica son diferenciales considerando la cantidad de contribuyentes o las descargas que puede recibir. Asimismo, cada uno de los contribuyentes tiene un área (compuesta de dos vertientes) y a su vez que determina una subcuenca.

En ese sentido, una cuenca hidrográfica se estructura en una determinada cantidad de subcuencas que serían sus contribuyentes o afluentes. Es decir, en una cuenca o subcuenca existirá solo un curso de agua de mayor nivel que recibe aportes de otras corrientes.

En este razonamiento cada subunidad (subcuenca) va estar compuesta de dos vertientes, que son sus laderas por donde va escurriendo el agua (previamente ingresa agua a la cuenca mediante la precipitación) hacia un colector común que siempre será un cauce. El proceso del drenaje en las laderas es bastante complejo, pero se puede sintetizar de la siguiente manera: una parte del agua se puede infiltrar debido a la porosidad o fracturamiento de roca, otra fracción lo va utilizar la vegetación y en parte lo puede devolver a la atmosfera mediante la transpiración. Asimismo, través de la evaporación del agua en los suelos húmedos puede retornar otra parte a la atmosfera. El volumen de agua resultante de la escorrentía en las laderas de las subcuencas va determinar una red de cauces. El área total de esa red de drenaje conformará la cuenca hidrográfica.

La forma de la cuenca y las subcuencas también pueden influir en el número de contribuyentes y en el volumen de descargas de cada cauce. Las cuencas con mayor redondez tendrán vertientes o laderas con mayor longitud que las más angostas y las posibilida- des de escurrir mayor volumen de agua en sus laderas será superior.

\section{Geomorfología y cabeceras de cuencas hidrográficas}

El objeto de la geomorfología es el relieve, que en concreto es una identificación y delimitación de geoformas interpretando su origen y dinámica actual. Los puntos más elevados de las geoformas positivas como por ejemplo montañas, volcanes, colinas y lomas se suelen utilizar la delimitar gran parte de una cuenca hidrográfica. Es decir, el carácter topográfico de las mencionadas geoformas se relacionan directamente con la delimitación de cuencas hidrográficas. Cabe agregar, que solo en el caso que las montañas hubiesen sido modeladas por la erosión glaciar se tendría puntos notorios o «elevados». Normalmente, serían geoformas de pirámides o circos glaciares con agujas y se podría señalar cotas de mayor elevación.

La precisión de las cotas en estos casos va depender de la información topográfica que se disponga (curvas de nivel) sino también de la precisión de la posición geodésica. En ese último aspecto va requerir un control de campo para que pueda considerarse que un levantamiento topográfico tenga una precisión geodésica. Normalmente, los estudios de cuencas hidrográficas tienen aplicación en el contexto ecológico, ambiental o de ordenamiento territorial, a escalas medianas o pequeñas, por esa razón no se suele considerar las mencionadas precisiones geodésicas. Sin embargo, si un estudio debido a sus objetivos requiere precisiones a escala grande se hace necesario elaborar una cartografía en base a una nivelación, fotografías o imágenes satelitales georreferenciado mediante con un control de campo.

El carácter litológico y estructural que tienen las geoformas como por ejemplo su deformación por plegamientos o fracturamientos pueden determinar formas cóncavas o convexas. Asimismo, esas particularidades tectónicas están relacionadas con la infiltración y la escorrentía en las vertientes de una cuenca.

Los patrones de drenaje es otro ejemplo de como se relaciona la geomorfología con las cuencas hidrográficas. Por ejemplo, las montañas de roca intrusivas poco permeables pueden determinar un patrón de drenaje dendrítico poco denso. Los volcanes determinan patrones de drenaje radial y pueden alimentar hidrográficamente a una subcuenca, por ejemplo, parte 
de la red de drenaje de laderas del volcán Coropuna, conforman la cabecera de la subcuenca del río Pampacolca, localizado en la parte alta de la Cuenca del río Majes en el Departamento de Arequipa.

En conclusión, las geoformas van a ser el soporte físico por donde se va materializar el ciclo hidrológico en cualquier cuenca o subcuenca.

\section{Los ecosistemas}

Los ecosistemas es el resultado de los procesos naturales de meteorización, erosión y formación de suelos que posteriormente son colonizados por una vegetación y que alberga una determinada fauna. Los factores climáticos entre ellos la precipitación es determinante en la constitución y la sostenibilidad de los ecosistemas.

Las geoformas típicas relacionadas con el agua superficial en las cabeceras de cuencas son, laderas de montańas con diferentes declives, afloramientos rocosos, glaciares con diferentes espesores, circos glaciares, morrenas, mesetas, entre otros. Esas geoformas se convierten en el soporte natural (inerte) de los ecosistemas.

$\mathrm{Si}$ relacionamos los cauces de las cabeceras de cuencas con los ecosistemas, encontramos que los orígenes de esas corrientes están vinculados a recurrentes ecosistemas como, por ejemplo, las lagunas, pastos, matorrales, bofedales, bosques, etc. Es decir, el relieve y agua son los dos principales elementos del ecosistema por su condición de soporte. La vegetación y la fauna es la parte biótica y serían el tercer y cuarto elemento del ecosistema.

\section{El problema de identificar cabeceras de cuencas hidrográficas}

\subsection{Antecedentes ambientales}

\section{Preocupación ambiental}

En el mundo el proceso de globalización se fue acelerando a partir de la década de los años de 1990 caracterizado por una fuerte urbanización, la degradación de ecosistemas frágiles, sobre todo en ecosistemas de montańa y el calentamiento global. Esa preocupación ambiental condujo a la celebración de la deno- minada Cumbre Mundial la Tierra, celebrada en Río de Janeiro, Brasil, en 1992.

\section{El desarrollo sostenible}

El resultado del mencionado evento mundial fue la promoción del modelo de desarrollo sostenible que intentaba realizar recomendaciones para desacelerar los cambios de uso de suelo incentivados por la inversión privada y pública en ecosistemas frágiles sobre todo de montaña. En ese plano, se tomó en cuenta la conservación o protección de ciertos ecosistemas por ser la fuente o base de recursos naturales como, por ejemplo, el agua, suelo o vegetación.

La teoría del desarrollo sostenible es una propuesta de carácter equitativo que considera a la sociedad como parte de un gran ecosistema llamado Tierra. En términos prácticos se refiere a incentivar que la explotación de los recursos naturales, no sólo satisfagan requerimientos actuales sino también evitar que se comprometa la satisfacción de necesidades de futuras generaciones.

Esas recomendaciones en realidad son lineamientos políticos que por su carácter espacial se relacionan con un modelo de Ordenamiento territorial.

\section{Marco legal}

Las mencionadas recomendaciones que se señala en el modelo de desarrollo sostenible han impactado en nuestro país mediante un marco legal tratando de adecuarse a la realidad del país. Las normas más importantes que se relacionan con las cuencas hidrográficas son las siguientes:

Ley $\mathrm{N}^{\circ}$ 28611, Ley General del Ambiente, de 15 de octubre de 2005, en su artículo 99 de los ecosistemas frágiles, en su enciso 99.2 «Los ecosistemas frágiles comprenden, entre otros, desiertos, tierras semiáridas, montańa, pantanos bofedales, bahías, islas pequeñas, humedales, lagunas alto andinas, lomas costeras, bosques de neblina y bosque relicto».

Ley $\mathrm{N}^{\circ}$ 29338, Ley de Recursos Hídricos, de 23 de marzo de 2009, en su artículo 98, Demarcación de cuencas hidrográficas, se señala que la Autoridad Nacional aprueba la demarcación territorial de las cuencas hidrográficas.

Ley $\mathrm{N}^{\circ} 30640$ de 16 de agosto de 2017, Ley que modifica la Ley $\mathrm{N}^{\circ}$ 29338, Ley de recursos hídricos, 
mediante el establecimiento de los criterios técnicos para la identificación y delimitación de las cabeceras de cuencas. $\mathrm{Al}$ respecto, se modifica el artículo 75 de la siguiente manera: «Artículo 75. Protección del Agua. El Estado reconoce como zonas ambientalmente vulnerables las cabeceras de cuenca donde se originan los cursos de agua de una red hidrográfica. La Autoridad Nacional, con opinión del Ministerio del Ambiente, puede declarar zonas intangibles en las que no se otorga ningún derecho para uso, disposición o vertimiento de agua. Asimismo, debe elaborar un Marco Metodológico de Criterios Técnicos para la Identificación, Delimitación y Zonificación de las Cabeceras de Cuenca de las Vertientes Hidrográficas del Pacífico, Atlántico y lago Titicaca».

\subsection{Problema para la identificación de cabeceras de cuencas}

Con la entrada en vigor de la mencionada Ley $\mathrm{N}^{\circ}$ 29338 se ha generado el siguiente problema:

¿Qué criterios técnicos contribuyen a identificar y delimitar cabeceras de cuencas hidrográficas?

\section{Antecedentes}

Analizando los antecedentes de cómo ha evolucionado los criterios geográficos, ecológicos y ambientales en nuestro país a partir de la Cumbre de Río de Janeiro 1992. Surge la preocupación por conservar los ecosistemas frágiles, como ejemplo se puede citar los humedales, lomas costeras y tierras semiáridas señalados en el año 2005 en la Ley General del Ambiente. Sin embargo, esos espacios se han urbanizados y transformado intensamente en los últimos veinte años. Por ejemplo, las denominadas tierras semiáridas comprenden los espacios donde pueden ocurrir movimientos en masa profundo, en particular en los torrentes mal denominadas en nuestro país como "quebradas secas». En esos torrentes sobre todo en sus terrazas y abanicos son impactados recurrentemente por deslizamientos o aluviones (huaycos) y se puede señalar los eventos ocurridos en meses de verano de los años 2015 y 2017 en todo el Perú. Justamente, el patrón de urbanización y también la infraestructura física coincide con esos espacios de «ecosistemas frágiles». Sobre ese último aspecto conviene recordar que la carretera central, una de las principales vías de nuestro país, corta innumerables torrentes y se encuentra expuesto al impacto de aluviones.

En el reciente dispositivo sobre la delimitación de cabeceras de cuencas que tienen la particularidad de tratar la misma preocupación, es decir la conservación de áreas con ecosistemas frágiles. Es una medida para proteger subunidades hidrográficas que dan origen a un río, mediante una zonificación.

\section{Objetivo general}

Del problema planteado se desprende el siguiente objetivo:

Determinar los criterios técnicos que contribuyen a identificar y delimitar cabeceras de cuencas hidrográficas.

\section{Métodos}

\subsection{Método de clasificación de cuencas de drenaje}

En el campo de geomorfología cuantitativa aplicado a la hidrología aparece el método para clasificar cuencas de drenaje que es muy antigua, pero vigente porque continúa teniendo una aplicación práctica en la actualidad. Mateo Gutiérrez Elorza en su libro Geomorfología sintetiza de la siguiente manera la aparición del mencionado método: «El estudio de los procesos, tanto en campo como en laboratorio, requiere de técnicas estadísticas que permitan elaborar adecuadamente los datos obtenidos. De aquí surge la Geomorfología cuantitativa, que tuvo un pionero en el ingeniero hidrólogo Horton (1945) en su trabajo sobre la morfometría de las cuencas de drenaje, que tuvo sus seguidores en Strahler (1952, 1956a, 1964) y Schumm (1956a)».

Conviene precisar que el referido método contiene dos aspectos o elementos interrelacionados primero el sistema de drenaje (red de drenaje) y segundo las cuencas de drenaje. El primero son líneas o segmentos de cauces (sin considerar el ancho del cauce) por donde circula el agua y el segundo el área que conforma una cuenca de drenaje. Toda cuenca de drenaje se descompone en dos vertientes (que son laderas inclinadas), por donde se produce la escorrentía.

El interés geomorfológico en este método ha sido su aplicación al estudio de vertientes o interfluvios, es 
decir, de los procesos de erosión que ocurren en las laderas como por ejemplo los deslizamientos y erosión hídrica. Para los fines geomorfológicos se suelen agregar aspectos morfométricos como la altura relativa de las geoformas, convirtiéndose en un tercer elemento. Los declives o pendientes de las geoformas se pueden considerar como un cuarto aspecto vinculado con la escorrentía y la erosión.

\section{El orden de cauces}

El orden de cauces o mejor dicho el orden de los segmentos de cauces porque sólo se tiene en cuenta las corrientes como si fuesen líneas. El orden de cauces consiste en definir primero la red total de segmentos de cauces y segundo señalar en cada uno de ellos un valor numérico entero.

Es decir, en esta clasificación sólo se va considerar el primer elemento explicado anteriormente. La clasificación de orden de cauces fue diseñada de manera pionera por Horton, considerando dos etapas.

La primera parte se inicia seńalando a todos los cauces que no tienen contribuyentes a los que les atribuye el valor de 1 (siendo el orden 1). La jerarquización continúa considerando que a partir del punto de confluencia de dos cauces de primer orden se origina a un cauce de orden 2. Prosigue el mismo criterio de coincidencia de confluencia de dos cauces de un mismo orden para determinar uno de orden superior. De esta manera la confluencia de dos cauces de orden 2 determinan uno de orden 3. Igualmente, la confluencia de dos cauces de tercer orden señala el inicio de un cauce de orden 4, así sucesivamente. En el caso que confluyan dos cauces de diferente orden, continua el orden de mayor valor. El orden de mayor valor es el número de orden que le corresponde a la cuenca.

La segunda etapa la clasificación de orden de cauces de Horton determinaba que el cauce de mayor orden proseguía aguas arriba hasta llegar al cauce de primer orden. Esta segunda parte de su clasificación fue abandonada por Strahler. La primera parte de la mencionada clasificación es la más usada universalmente y se suelo llamar la clasificación de Horton - Strahler.

Cabe agregar, como resultado del mencionado modelo o clasificación de orden de cauces se establecen segmentos de cauces individuales, el de mayor orden será el valor de que le corresponde a la cuenca. El área total de la cuenca tendrá un solo orden que será el número valor y cada uno del resto de segmentos de cauces generará una subárea o subcuenca. Como resultado se obtendrán una cuenca que incluyen un determinado número de subcuencas. El método de orden es de tipo cualitativo, normalmente, un cauce con determinado orden tiene un caudal que se vincula con el mencionado nivel jerárquico.

Se advierte que para llevar a la práctica la mencionada metodología hay que definir primero la escala de trabajo y hacer un levantamiento de la red de drenaje teniendo como fuente las imágenes de satélite o fotografías aéreas, de lo contrario se pueden obtener errores. En ese sentido, lo recomendable para el caso de aplicarlo en el Perú se tendría que disponer de la red de drenaje para todo el Perú, de preferencia en formato shape file, a diversas escalas con el fin que todos los usuarios, sobre todo las instituciones, utilicen la misma información. Se recomienda contar la mencionada información geoespacial a escalas 1: 100 000, 1: 50000 y 1: 25000 .

\subsection{Otras metodologias para identificar cabeceras de cuencas}

Criterios climáticos y altitudinales. El uso de la variable precipitación para determinar las "Cuencas secas" y las "Cuencas húmedas», es decir, la cantidad de agua que ingresa a la cuenca. Antecedentes del uso del mencionado criterio lo encontramos en los «Inventarios, evaluación y uso racional de los recursos naturales de la Costa», para diversas cuencas hidrográficas preparados por la Oficina Nacional de Evaluación de Recursos Naturales (ONER) en la década de los años de 1970 en nuestro país. En estos trabajos pioneros realizados en las cuencas hidrográficas de la vertiente del Pacífico del Perú, las «cuencas secas» o «cuencas húmedas» se delimitaban en base a las altitudes. Es decir, determinadas altitudes se correlacionaban con bajas o altas precipitaciones. Por ejemplo, la ONER, para las cuencas de los ríos Chilca, Mala y Asia, señalaba que la «cuenca seca» comprendía entre el nivel del mar y la cota de los 2,000 m.s.n.m. donde la precipitación es menor a $250 \mathrm{~mm}$. Mientras que el resto comprendía la "cuenca húmeda» espacio entre los 2,000 m.s.n.m. y la divisoria cordillerana, indicando una precipitación anual entre 250 y $1,000 \mathrm{~mm}$. 
Se observa, que en nuestro país todavía se sigue considerando el referido criterio climático y altitudinal. En ese sentido, se ha encontrado que se utilizan algunas de los las líneas de isoyetas para delimitar la denominada "cuenca húmeda». En este caso esa «cuenca húmeda» se suele considerar como cabecera de cuenca, con lo cual solo se estaría utilizando como único criterio la variable precipitación.

La desventaja de utilizar los referidos criterios sería en la dificultad de disponer suficientes estaciones climatológicas en las cabeceras de cuenca para preparar isoyetas con cierto grado de confiabilidad. Otra dificultad sería la proyección de esas isoyetas en el terreno porque las líneas altitudinales no siempre van a coincidir con los niveles de precipitación debido a que la atmosfera es muy compleja y dinámica.

$\mathrm{Al}$ igual que en el criterio anterior se tiene que advertir que si se decide utilizar el mencionado criterio climático y altitudinal para identificar cabeceras de cuenca, se tendría que hacer un levantamiento de isoyetas para todas las cuencas hidrográficas del país, recomendable en formato shape file. Un criterio adicional sería considerar las áreas de lagunas y glaciares delimitados por la isoyeta más cercana.

\section{Aplicaciones}

\subsection{Caso aplicado: Cuencas de los ríos Acaríy Grande - Información temática}

Se ha preparado una base de datos para los casos de las cuencas de los ríos Acarí y Grande, para identificar las cabeceras de cuenca siguiendo los criterios de cuenca de drenaje (orden de cauces) y «cuencas húmedas». Ambas unidades hidrográficas se localizan en la vertiente del Pacifico peruano, como referencia se tiene a la localidad de Nazca en la cuenca del río Grande y la de Acarí en la cuenca del mismo nombre. Se utilizó como herramienta el software Arcmap para disponer de las siguientes capas temáticas en formato shape file: curvas de nivel, drenaje (ríos y quebradas), subcuencas de drenaje, isoyetas. Inicialmente se obtuvó las curvas de nivel y red de drenaje de las Cartas Nacionales, a escala 1: 100000 del Instituto Geográfico Nacional, para el caso de la digitalización de las isoyetas se utilizó la información de la Autoridad Nacional del Agua (ANA). Posteriormente, se trabajó a una escala 1: 50000 para lo cual se levantó mayor drenaje, mediante la interpretación imágenes de satélite y uso de las herramientas del software Arcmap.

\subsection{Identificación de cabeceras de cuenca siguiendo criterio de cuencas de drenaje}

Como se explicó anteriormente este método tiene como insumo el orden de cauces posteriormente se procede a delimitar las subcuencas de drenaje desde los de primer orden hasta el de mayor valor que representa el número de orden de la unidad hidrográfica (cuenca). Dependiendo de la naturaleza de la cuenca se pueden preparar mapas con subcuencas de tercer, cuarto a mayor orden y de esta manera se puede identificar con relativa facilidad la cabecera de cuenca. Las subcuencas de menor orden van a contribuir hidrológicamente a las subcuencas de mayor orden.

En el Anexo Nro. 1 se acompaña el gráfico "Orden de cauces de las cuencas de los ríos Grande y Acari» pertenecientes a la vertiente del Pacifico. En ese gráfico se puede observar la red de drenaje y el orden correspondiente. La Cuenca del río Grande tiene un orden 7, mientras que a la Cuenca del río Acarí le corresponde el orden 5 .

En el Anexo Nro. 2 se encuentra el gráfico "Cabeceras de las cuencas de los ríos Grande y Acarí». En ese gráfico se puede visualizar que la cabecera de la cuenca del río Grande está conformado por dos subcuencas de orden 6. En cambio, la cabecera de la cuenca del río Acarí está constituido por dos subcuencas de orden 4 .

Como se puede observar ambas cuencas son diferentes en cuanto a forma sobre todo la cabecera, la cuenca del río Grande es "redondeado", en tanto la cuenca del río Acarí es alargado. Para el caso de la cuenca del río Acari, la cabecera está confinado a la parte de mayor elevación. En cambio, la cabecera de la cuenca del río Grande es enorme y abarca gran parte de la unidad hidrográfica. Aquí conviene recordar que la denominación de "cabecera" se refiere al aspecto morfológico o fisiográfico del contorno de la cuenca como unidad hidrográfica, aspecto que se puede visualizar con mayor nitidez en el caso de Acarí.

\subsection{Identificación de cabeceras de cuenca siguiendo criterio de cuencas húmedas}


Para el caso de la identificación de las cabeceras de cuenca siguiendo el criterio de "cuenca húmeda» se consideró las isoyetas que cubren el área de las mencionadas unidades hidrográficas.

En estos casos se pueden señalar la isoyeta de mayor valor pata identificar la cabecera de cuenca.

En el Anexo Nro. 3 se acompańa el gráfico "Cuencas húmedas de cuencas de los ríos Grande y Acarí». En ese grafico se puede observar que la isoyeta que indica el mayor valor de la cuenca del río Grande es $500 \mathrm{~mm}$. Sin embargo, correspondería a una cuenca de clima semiárido, es decir con escasa precipitación. En todo caso, a modo de ejercicio se ha considerado este valor para seńalar la "cuenca humedad» de la unidad hidrográfica. Para el caso de la cuenca del río Acarí, la isoyeta de mayor valor es de $700 \mathrm{~mm}$.

\section{Discusión de resultados}

En esta parte vamos a señalar las ventajas y desventajas de considerar las dos metodologías planteadas en este trabajo para identificar cabeceras de cuencas.

\subsection{Cuencas de drenaje}

Para la aplicación del método de cuencas de drenaje para identificar cabeceras de cuenca se tiene la ventaja de que quedaría plenamente delimitada tal como se muestra en el ejercicio presentado para el caso de las Cuencas hidrográficas de Grande y Acarí. Operativamente este método se lleva a la práctica utilizando la clasificación de orden de cauces y que universalmente se emplea sin discusión porque determinada un valor numérico a cada cauce que a su vez forma una subcuenca.

La desventaja es que en muchos casos la cabecera que determina este método corresponden a un área muy grande debido a su forma, geología y geomorfología. Desventaja en el contexto de planificación porque una gran área de la cuenca se estaría zonificando como un espacio de conservación o protección. Observando el Anexo Nro. 1, la forma de la cuenca del río Grande es «redondeada». La parte de su «cabecera» localizada aledańa a Acarí, comprende aparatos volcánicos y flujos de piroclásticos. La parte más alta de la cabecera ha sido erosionada por masas glaciares encontrándose áreas con morrenas. El patrón de drenaje resultante es paralelo que es característico de las rocas volcánicas. La "parte baja» de esta cabecera está compuesto por una serie de abanicos aluviales. En resumen, si bien es cierto el referido método es muy útil para determinar cabeceras de cuenca, sin embargo, para los casos que las cabeceras sean enormes por factores geológico y geomorfológicos podría no ser convenientes para fines de planificación.

\subsection{Cuencas húmedas}

La ventaja de emplear el señalamiento de las cabeceras de cuenca siguiendo el criterio de "cuenca húmeda», sería conocer las áreas donde ingresa mayor cantidad de agua por precipitación. El mencionado criterio podría complementarse con la identificación de lagunas, incluso con la vegetación por ejemplo, los bofedales. Es decir, la ventaja sería identificar la mayor cantidad de agua considerando el factor precipitación.

La desventaja sería que no se está incluyendo el criterio hidrológico para conocer la disponibilidad de agua en los cauces. En estos casos primero cualitativamente con el orden de cauce y posteriormente su relación con los caudales.

Otra desventaja sería que el nivel de las isoyetas es dinámico debido a la complejidad de la atmosfera y dificultad para proyectarlo al terreno. En el ejercicio planteado en ambas cabeceras de cuencas (Grande y Acarí) predomina el clima semi-arido por lo tanto, la «cuenca húmeda» está prácticamente ausente.

\section{Conclusiones}

Independientemente del criterio que se utilice para identificar cabeceras de cuenca se requiere previamente disponer de una base de datos estandarizada a nivel nacional. Por ejemplo, la información geoespacial que debe contener esa Base de Datos entre otros es la red de drenaje, cuerpos de agua y líneas de isoyetas a diferentes escalas espaciales. Igualmente, curvas de nivel a diferentes escalas.

Las áreas de las cabeceras de cuencas se deben a factores geológicos, geomorfológicos, climáticos e hidrológicos. Por esa razón, es posible que una cabecera de cuenca pueda ser gran área o muy pequeńa. Esta 
situación podría originar dificultades a la hora de delimitar cabeceras de cuenca con fines de planificación.

Se puede dar el caso que una cuenca en su totalidad este dominada por climas aridos y semi-aridos, es decir con escasa disponibilidad de agua y difícilmente se pueda señalar un espacio como "cuenca humeda».

El criterio de la determinación de cuencas de drenaje mediante el empleo del orden de cauces es el método idóneo para delimitar cabeceras de cuenca. Sin embargo, cuando se trata de objetivos de planificación se podría hacer adecuaciones, por ejemplo, identificar las partes de las cabeceras de cuencas que tienen mayor disponibilidad de agua.

El criterio de "cuenca húmeda» se basa en aspectos climáticos y si puede complementar considerando ciertos ecosistemas que están relacionados con el agua en "tierra», como son las áreas con lagunas y bofedales.

\section{Referencias bibliográficas}

Carenas, María y Jorge Giner (2014). Geología. Madrid: Lavel Industria Gráfica.

Dávila, Jorge (2011). Diccionario geológico. Lima.

Pedraza, Javier de (1996). Geomorfología - Principios, métodos y aplicaciones. Madrid: Editorial Rueda.

Lugo Hup, José (1989). Diccionario geomorfológico. México: UNAM.

Gutiérrez, Mateo (2008). Geomorfología. Madrid: Gráficas Estela, S.L.

Oficina Nacional de Evaluación de Recursos NATURAles - ONER (1976). Inventario, evaluación y uso racional de los recursos naturales de la Costa Cuencas de los ríos Chilca, Mala y Asia - volumen 1. Lima. 
Anexo 1

Orden de cauces de las cuencas de los ríos Grande y Acarí

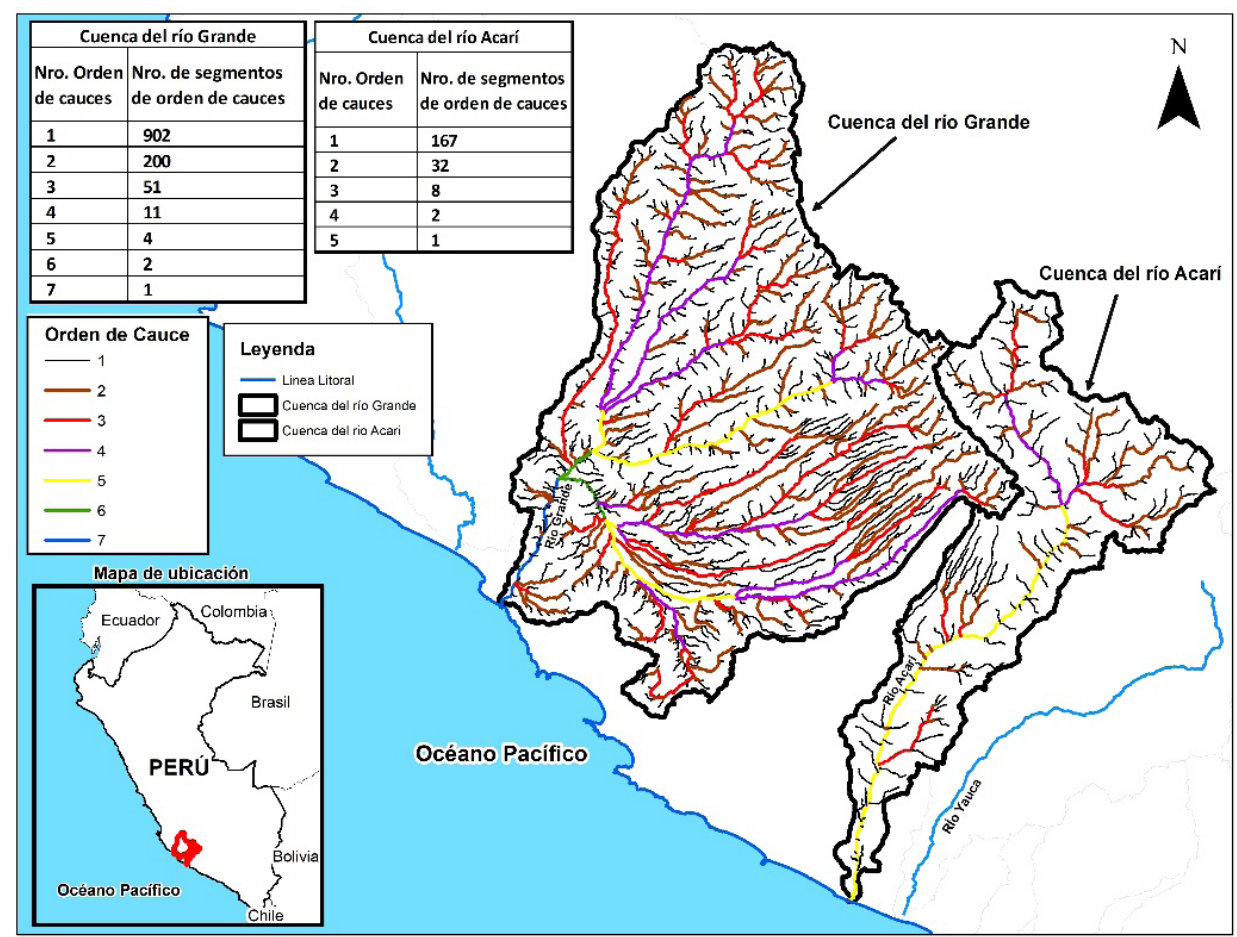

Anexo 2

Cabeceras de las cuencas de los ríos Grande y Acarí

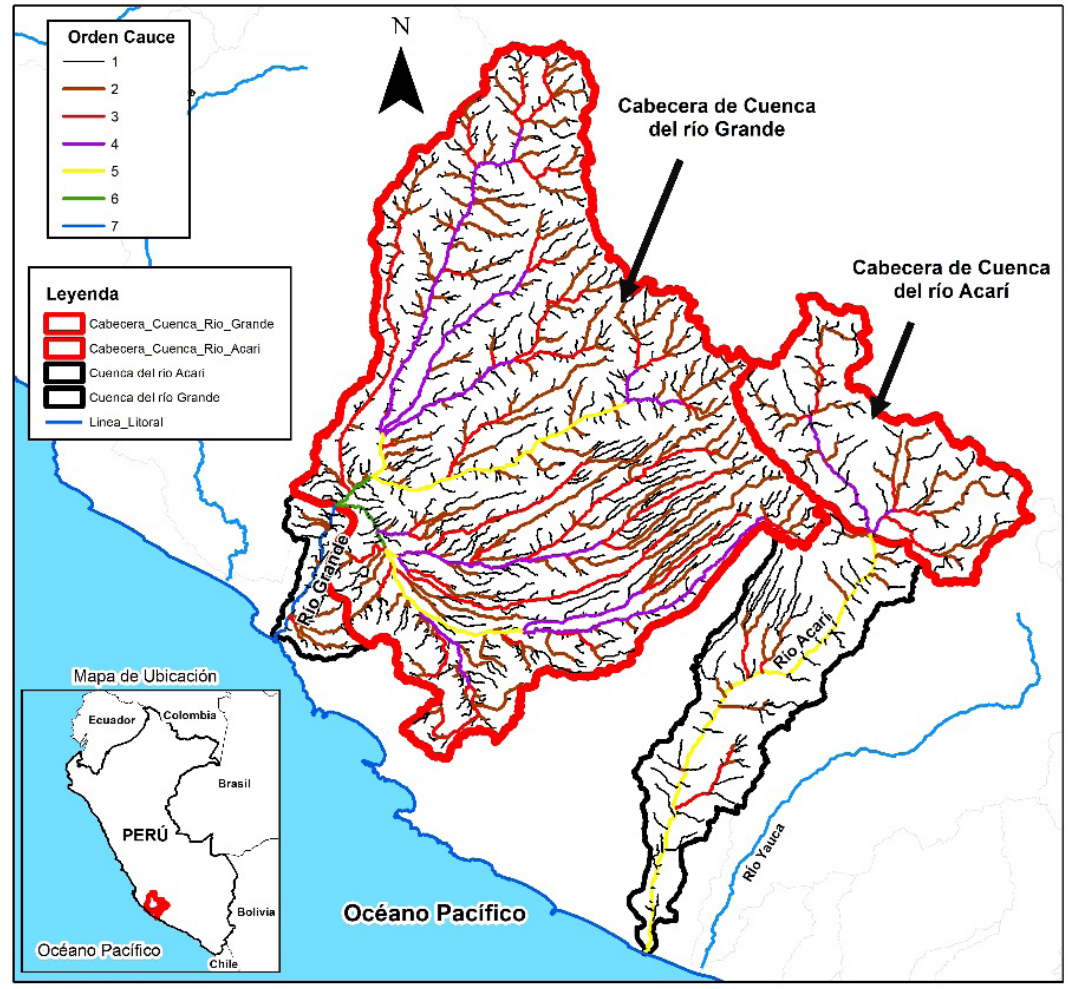




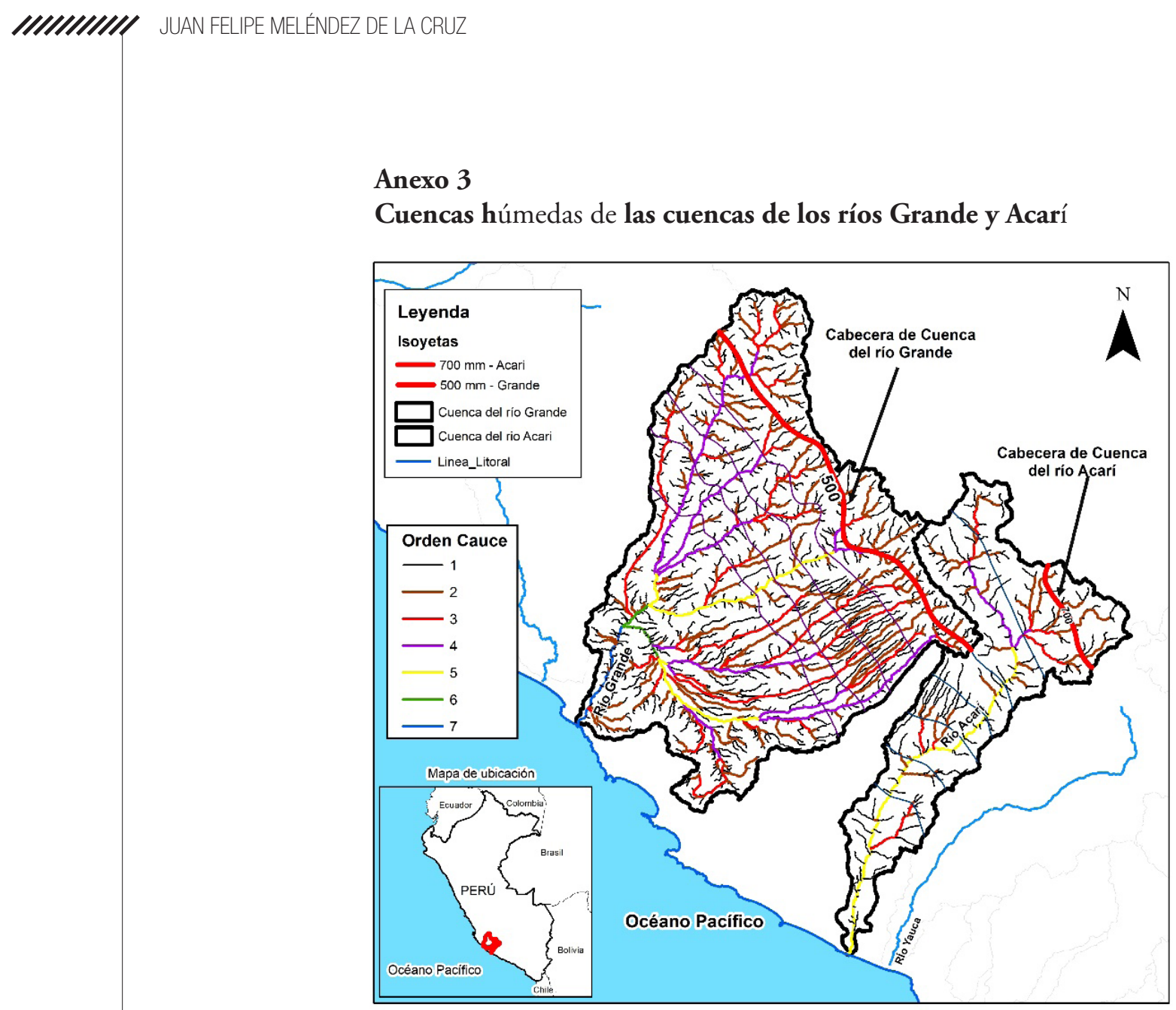

